Nasry Jassim Hussien, Siti Fairus M. Yusoff*, Mohamad J. Al-Jeboori*, Yang Farina, Hamza M. Abosadiya, Enaam I. Yousif and Riyadh M. Ahmed

\title{
Crystal structure of $\boldsymbol{N}$-phenyl-2-(propan-2- ylidene)hydrazine-1-carbothioamide, $\mathrm{C}_{10} \mathrm{H}_{13} \mathrm{~N}_{3} \mathrm{~S}$
}

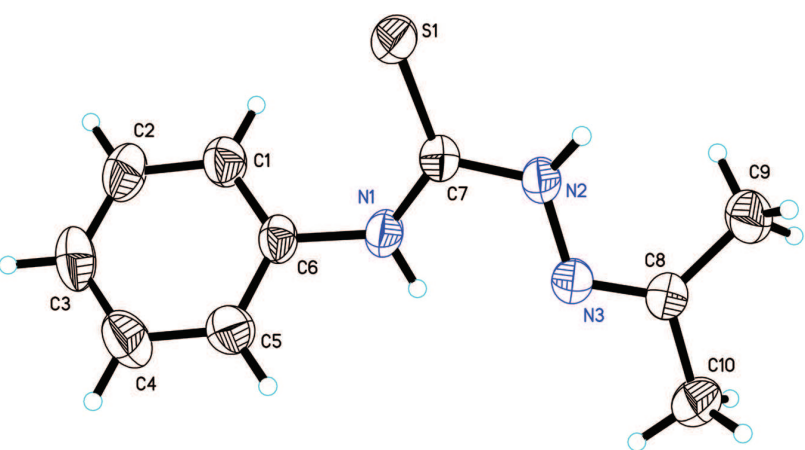

https://doi.org/10.1515/ncrs-2018-0080

Received July 17, 2018; accepted September 9, 2018; available online September 27, 2018

\section{Abstract}

$\mathrm{C}_{10} \mathrm{H}_{13} \mathrm{~N}_{3} \mathrm{~S}$, monoclinic, $P 2_{1} / c$ (no. 14), $a=12.2463(8) \AA$, $b=7.6397(5) \AA, \quad c=11.6544(9) \AA, \quad \beta=102.684(2)^{\circ}$, $V=1060.72(11) \AA^{3}, Z=4, R_{\mathrm{gt}}(F)=0.0448, w R_{\mathrm{ref}}\left(F^{2}\right)=0.1211$, $T=301(2) \mathrm{K}$.

\section{CCDC no.: 1558277}

The crystal structure is shown in the figure. Tables 1 and 2 contain details on crystal structure and measurement conditions

*Corresponding authors: Siti Fairus M. Yusoff, School of Chemical Sciences and Food Technology, Faculty of Science and Technology, Universiti Kebangsaan Malaysia, 43600 UKM Bangi, Selangor, Malaysia, e-mail: sitifairus@ukm.edu.my; and Mohamad J. Al-Jeboori, Department of Chemistry, College of Education for Pure Science (Ibn Al-Haitham), University of Baghdad, Baghdad, Iraq, e-mail: mohamadaljeboori@yahoo.com

Nasry Jassim Hussien: School of Chemical Sciences and Food Technology, Faculty of Science and Technology, Universiti Kebangsaan Malaysia, 43600 UKM Bangi, Selangor, Malaysia; and Department of Chemistry, College of Education for Pure Science, Diyala University, Diyala, Iraq

Yang Farina: School of Chemical Sciences and Food Technology, Faculty of Science and Technology, Universiti Kebangsaan Malaysia, 43600 UKM Bangi, Selangor, Malaysia

Hamza M. Abosadiya: Department of Chemistry, Faculty of Science, Baniwaleed University, Bani Walid, Libya

Enaam I. Yousif and Riyadh M. Ahmed: Department of Chemistry, College of Education for Pure Science (Ibn Al-Haitham), University of Baghdad, Baghdad, Iraq
Table 1: Data collection and handling.

\begin{tabular}{ll}
\hline Crystal: & Size $0.60 \times 0.40 \times 0.32 \mathrm{~mm}$ \\
Wavelength: & Mo $K \alpha$ radiation $(0.71073 \AA$ 文 \\
$\mu:$ & $0.27 \mathrm{~mm}^{-1}$ \\
Diffractometer, scan mode: & Bruker SMART, $\varphi$ and $\omega$-scans \\
$\theta_{\max }$, completeness: & $28.4^{\circ},>99 \%$ \\
$N(h k l)_{\text {measured }}, N(h k l)_{\text {unique }}, R_{\text {int }}:$ & $37336,2646,0.039$ \\
Criterion for $I_{\text {obs }}, N(h k l)_{\text {gt }}:$ & $I_{\text {obs }}>2 \sigma\left(I_{\text {obs }}\right), 2126$ \\
$N(\text { param })_{\text {refined }}:$ & 138 \\
Programs: & Bruker programs [1], SHELX [2], \\
& PLATON [3] \\
\hline
\end{tabular}

Table 2: Fractional atomic coordinates and isotropic or equivalent isotropic displacement parameters $\left(\AA^{2}\right)$.

\begin{tabular}{lrrrr}
\hline Atom & $\boldsymbol{x}$ & $\boldsymbol{y}$ & $\boldsymbol{z}$ & $\boldsymbol{U}_{\text {iso }}{ }^{*} \boldsymbol{U}_{\text {eq }}$ \\
\hline S1 & $0.16731(4)$ & $0.89118(7)$ & $0.53541(4)$ & $0.04377(18)$ \\
N1 & $0.20128(12)$ & $0.8324(2)$ & $0.31739(13)$ & $0.0407(4)$ \\
N2 & $0.02253(11)$ & $0.8844(2)$ & $0.33278(13)$ & $0.0377(3)$ \\
N3 & $-0.00346(12)$ & $0.8913(2)$ & $0.21013(13)$ & $0.0385(3)$ \\
C1 & $0.38114(15)$ & $0.7416(3)$ & $0.44260(18)$ & $0.0452(4)$ \\
H1 & 0.3443 & 0.6781 & 0.4909 & $0.054^{*}$ \\
C2 & $0.49744(16)$ & $0.7471(3)$ & $0.46641(19)$ & $0.0531(5)$ \\
H2 & 0.5385 & 0.6882 & 0.5317 & $0.064^{*}$ \\
C3 & $0.55231(16)$ & $0.8385(3)$ & $0.3947(2)$ & $0.0540(5)$ \\
H3 & 0.6302 & 0.8420 & 0.4116 & $0.065^{*}$ \\
C4 & $0.49191(17)$ & $0.9249(3)$ & $0.2977(2)$ & $0.0570(6)$ \\
H4 & 0.5290 & 0.9863 & 0.2487 & $0.068^{*}$ \\
C5 & $0.37579(16)$ & $0.9206(3)$ & $0.27298(18)$ & $0.0477(5)$ \\
H5 & 0.3350 & 0.9777 & 0.2068 & $0.057^{*}$ \\
C6 & $0.32076(13)$ & $0.8312(2)$ & $0.34670(15)$ & $0.0360(4)$ \\
C7 & $0.13079(13)$ & $0.8690(2)$ & $0.38853(15)$ & $0.0333(4)$ \\
C8 & $-0.10561(14)$ & $0.8704(2)$ & $0.15745(15)$ & $0.0348(4)$ \\
C9 & $-0.20087(16)$ & $0.8323(3)$ & $0.21445(18)$ & $0.0545(5)$ \\
H9A & -0.1736 & 0.7713 & 0.2872 & $0.082^{*}$ \\
H9B & -0.2550 & 0.7606 & 0.1631 & $0.082^{*}$ \\
H9C & -0.2354 & 0.9402 & 0.2298 & $0.082^{*}$ \\
C10 & $-0.13165(17)$ & $0.8822(3)$ & $0.02644(16)$ & $0.0488(5)$ \\
H10A & -0.1743 & 0.9865 & 0.0020 & $0.073^{*}$ \\
H10B & -0.1744 & 0.7815 & -0.0062 & $0.073^{*}$ \\
H10C & -0.0630 & 0.8860 & -0.0008 & $0.073^{*}$ \\
H1A & $0.1695(16)$ & $0.837(3)$ & $0.2429(9)$ & $0.047(6)^{*}$ \\
H2A & $-0.0235(15)$ & $0.924(3)$ & $0.3739(16)$ & $0.050(6)^{*}$ \\
\hline & & & &
\end{tabular}


and a list of the atoms including atomic coordinates and displacement parameters.

\section{Source of material}

A mixture of $(1.36 \mathrm{~g}, 0.01 \mathrm{~mol})$ of diethylcarbamoyl chloride and $(0.76 \mathrm{~g}, 0.01 \mathrm{~mol})$ of ammonium thiocyanate in $40 \mathrm{ml}$ acetone was stirred and heated to reflux for $3 \mathrm{~h}$ [4]. The mixture was cooled, and then filtered off. A solution of 4-phenyl-3thiosemicarbazide $(1.67 \mathrm{~g}, 0.01 \mathrm{~mol})$ in $20 \mathrm{ml}$ of acetone was added to the filtrate. The reaction mixture was heated to reflux for $2 \mathrm{~h}$, and then allowed to cool at room temperature to give the title compound as colorless crystals. Yield: $46 \%$ mp.: $197-199^{\circ} \mathrm{C}$.

\section{Experimental details}

Hydrogen atoms were placed in their geometrically idealized positions (SHELX System [2]) and constrained to ride on their parent atoms.

\section{Discussion}

The formation of Schiff bases, which are a remarkable species, has played a vital role in the development of organic and coordination chemistry [5, 6]. This is due to their unique properties and their wide range of applications [7-13].

$N$-phenyl-2-(propan-2-ylidene)hydrazine-1-carbothioamide, $\mathrm{C}_{10} \mathrm{H}_{13} \mathrm{~N}_{3} \mathrm{~S}$, crystalize as a monoclinic crystal system with space group of $P 2_{1} / c$. The X-ray single-crystal investigation showed that, the formation of Schiff base has been achieved upon the reaction of the primary amine group of thiosemicarbazide with the carbonyl group of acetone solvent. The molecule of the compound $N$-phenyl-2-(propan2-ylidene)hydrazine-1-carbothioamide is discrete and the asymmetric unit consist of one molecule ( $c f$. the figure)). The central thiourea moiety [S1/N1/N2/C7] is essentially planar with a maximum deviation of 0.005(2) Å for atom $\mathrm{C} 7$ from least-squares plane. The mean plane of the central of thiourea moiety makes a dihedral angle of $43.98(12)^{\circ}$ with the mean plane phenyl ring (C1-C6). The bond length of azomethine group $\mathrm{C} 8=\mathrm{N} 3$ is $1.275(2) \AA$. Analysis data indicated all bond lengths and angles of the molecule are unexceptional [14, 15].

Acknowledgements: The authors would like to thank Universiti Kebangsaan Malaysia for research grants (GUP-2017004). We also acknowledge Diyala, and Baghdad Universities for their continued support. We would like to thank the Ministry of Higher Education and Scientific Research in IRAQ for the PhD scholarship for Mr. NASRY JASSIM.

\section{References}

1. Bruker: SMART, SAINT and SADABS. Bruker AXS Inc., Madison, WI, USA (2009).

2. Sheldrick, G. M.: A short history of SHELX. Acta Crystallogr. A64 (2008) 112-122.

3. Spek, A. L.: Structure validation in chemical crystallography. Acta Crystallogr. D65 (2009) 148-155.

4. Hussien, N. J.; Yusoff, S. F. M.; El-Hiti, G. A.; Farina, Y.; Al-Jeboori, M. J.; Yousif, E.: Crystal structure of 1(4,4-dimethyl-2,6-dithioxo-1,3,5-triazinan-1-yl)-3(diethylaminocarbonyl)thiourea, $\mathrm{C}_{11} \mathrm{H}_{20} \mathrm{~N}_{6} \mathrm{OS}_{3}$. Z. Kristallogr. 232 (2017) 325-326.

5. Yinghua, J.; Youlong, Z.; Wei, Z.: Development of organic porous materials through Schiff-base chemistry. CrystEngComm. 15 (2013) 1484-1499.

6. Shiu, K. B.; Liu, S. A.; Lee, G. H.: One-pot conditional selfassembly of multicopper metallacycles. Inorg. Chem. 49 (2010) 9902-9908.

7. Enis, N. M. Y.; Thahira, B. S. A. R.; Edward, R. T. T.; Abhimanyu, V.; Karen, A. C.; Mohamed, I. M. T.; Haslina, A.: Synthesis, characterization and biological evaluation of transition metal complexes derived from N, S bidentate ligands. Int. J. Mol. Sci. 16 (2015) 11034-11054.

8. Gomathi, V.; Selvameena, R.: Synthesis, characterisation and biological studies of complexes of 3D transition metals and with Schiff base derived from sulfadiazine and 2-acetylnaphthalene. Int. J. Recent Sci. Res. 4 (2013) 94-97.

9. Shivakumar, K.; Shashidhar, P.; Vithal, R. P.; Halli, M. B.: Synthesis, spectral characterization and biological activity of benzofuran Schiff bases with Co(II), Ni(II), Cu(II), Zn(II), Cd(II) and $\mathrm{Hg}(\mathrm{II})$ complexes. J. Coord. Chem. 61 (2008) 2274-2287.

10. Hunashal, R. D.; Satyanarayana, D.: One pot synthesis of 3-(substituted phenoxymethyl)-6-phenyl/substituted phenoxymethyl-1,2,4-triazolo[3,4-b][1, 3, 4] thiadiazole derivatives as antimicrobial agents. Int. J. Pharm. Biol. Sci. 3 (2012) 183-192.

11. Tarafder, M. T. H.; Ali, M. A.; Wee, D. J.; Azahari, K.; Silong, S.; Crowse, K. A.: Complexes of a tridentate ONS Schiff base. Synthesis and biological properties. Transit. Metal Chem. 25 (2000) 456-460.

12. Dharamraj, N.; Viswanathanmurthi, P.; Natarajan, K.: Ruthenium (II) complexes containing bidentate Schiff bases and their antifungal activity. Transit. Metal Chem. 26 (2001) 105-109.

13. Ejiah, F. N.; Fasina, T. M.; Familoni, O. B.; Ogunsola, F. T.: Substituent effect on spectral and antimicrobial activity of Schiff bases derived from aminobenzoic acids. Adv. Biol. Chem. 3 (2013) 475-479.

14. Liu, C.: Crystal structure of (E)-2-(anthracen-9-ylmethylene) hydrazine-1-carbothioamide, $\mathrm{C}_{16} \mathrm{H}_{13} \mathrm{~N}_{3} \mathrm{~S}$. Z. Kristallogr. NCS 233 (2018) 315-316.

15. Oliveira, A. B.; Beck, J.; Landvogt, C.; Feitosa, B. R. S.; Rocha, F. V.: Crystal structure of (E)-2-[4-(4-hydroxyphenyl)butan-2ylidene]hydrazine-1-carbothioamide. Acta Crystallogr. E 71 (2015), 033-034. 